\title{
Erratum to: Completing a new official history: significance of White-Deer Plain
}

\section{Yuan Gao}

Published online: 7 June 2014

(C) Akadémiai Kiadó, Budapest, Hungary 2014

\section{Erratum to: Neohelicon \\ DOI 10.1007/s11059-013-0213-x}

After the publication of the paper "Completing a new official history: significance of White-Deer Plain" I realized that some of the bibliographical data in the "References" section are incomplete or inaccurate. In what follows readers can find the corrections.

1. Che, B. (2004). Bailuyuan xiuding ban yu yuanban shan'gai bijiao yanjiu [A comparative study of the original and revised editions of White-Deer Plain]. Tangdu Xuekan [Tangdu Journal], 5.

Correct: Che, B. (2004). Bailuyuan xiuding ban yu yuanban shan'gai bijiao yanjiu [A comparative study of the original and revised editions of WhiteDeer Plain]. Tangdu Xuekan [Tangdu Journal], 5, 11-17.

2. Chun, A. (1996). Fuck Chineseness: On the ambiguity of ethnicity as culture as identity. Boundary 2, 23(2), 111-138.

Correct: Chun, A. (1996). Fuck Chineseness: On the ambiguities of ethnicity as culture as identity. Boundary 2, 23(2), 111-138.

3. Duara, P. (1993). De-constructing the Chinese nation. The Australian Journal of Chinese Affairs, 30, 1-16.

The online version of the original article can be found under doi:10.1007/s11059-013-0213-x.

Y. Gao $(\bowtie)$

Department of History, Southern Illinois University Carbondale, 1000 Faner Drive, Rm 3374,

Mailcode 4519, Carbondale, IL 62901, USA

e-mail:ygao@siu.edu; jfkrn@yahoo.com 
Correct: Duara, P. (1993). De-constructing the Chinese nation. The Australian Journal of Chinese Affairs, 30, 1-26.

4. He, J. (2010). Xin qimeng zhishi dang'an: bashi niandai zhongguo wenhua уапjiu [On the New Enlightenment: Studies on Chinese Culture in the 1980s]. Beijing: Beijing University.

Correct: He, J. (2010). Xin qimeng zhishi dang'an: bashi niandai zhongguo wenhua yаnjiu [On the New Enlightenment: Studies on Chinese Culture in the 1980 s]. Beijing: Beijing University Press.

5. Lei, D. (1993). Feixu shang de jinghun [The soul in the ruined region]. Wenxue Pinglun [Literary Review], 6.

Correct: Lei, D. (1993). Feixu shang de jinghun [The soul in the ruined region]. Wenxue Pinglun [Literary Review], 6, 106-119.

6. Li, J. (Ed.). (2000a). Baoluyuan pinglun ji [Anthology on White-Deer Plain]. Beijing: Renmin Wenxue Chubanshe.

Correct: Li, J. (Ed.). (2000a). Bailuyuan pinglun ji [Anthology on WhiteDeer Plain]. Beijing: Renmin Wenxue Chubanshe.

7. Link, P. (2000). The uses of literature: Life in the socialist Chinese system. Princeton, NJ: Princeton University Press.

Correct: Link, P. (2000). The uses of literature: Life in the socialist Chinese literary system. Princeton, NJ: Princeton University Press.

8. Liu, J. (2004a). Revolution plus love: Literary history, women's bodies, and thematic repetition. Honolulu, HI: University of Hawaii Press.

Correct: Liu, J. (2004a). Revolution plus love: Literary history, women's bodies, and thematic repetition in twentieth-century Chinese fiction. Honolulu, HI: University of Hawaii Press.

9. Liu, K. (2004b). Globalization and cultural trend in China. Honolulu, HI: University of Hawaii.

Correct: Liu, K. (2004b). Globalization and cultural trends in China. Honolulu, HI: University of Hawaii.

10. Tang, Y. (1995). Wenhua re he Guoxue re [Cultural fever and the fever of national studies]. Twenty-first Century, Issue 31.

Correct: Tang, Y. (1995). Wenhua re he Guoxue re [Cultural fever and the fever of national studies]. Ershi Yi Shijie [Twenty-First Century], 31, 32-35.

11. Xu, Z. (1994). Dangdai xiaoshuo zhong de xiandai shi: lun hongqi pu, lingqi, danian he bailuyuan [Modern history in contemporary fiction: On Hongqi Pu (Keeping the red flag flying), "Ling Qi" (The miraculous flag), "Da Nian" (The New Year), Bailu Yuan [White-Deer Plain]. Shanghai Wenxue [Shanghai Literature], 10. 
Correct: Xu, Z. (1994). Dangdai xiaoshuo zhong de xiandai shi: lun Hongqi pu, Lingqi, Danian he Bailuyuan [Modern history in contemporary fiction: On Hongqi Pu (Keeping the red flag flying), "Ling Qi" (The miraculous flag), "Da Nian" (The New Year), Bailu Yuan (White-Deer Plain)]. Shanghai Wenxue [Shanghai Literature], 10, 73-80.

12. Yang, L. (2012). Bailuyuan guoshen zaijian si fenzhong, suojianban ren you shasheng li [White-Deer Plain still hilarious though four minutes cut]. Xinjing Bao [The Beijing News], April 6.

Correct: Yang, L. (2012). Bailuyuan guozhen zaijian si fenzhong, suojianban ren you shasheng li [White-Deer Plain still hilarious though four minutes cut]. Xinjing Bao [The Beijing News], April 6.

13. Yang, Q. (2010). Shanghai yu 'chongxie wenxue shi de fasheng' [Shanghai and the appearance of Rewriting Literary History']. Xiandai Zhongwen Xuekan [Journal of Modern Chinese Studies], 3.

Correct: Yang, Q. (2010). Shanghai yu 'chongxie wenxue shi de fasheng' [Shanghai and the appearance of Rewriting Literary History']. Xiandai Zhongwen Xuekan [Journal of Modern Chinese Studies], 3, 47-53.

14. Zhang, X. (1997). The era of Chinese reform: Cultural fever, Avant-Garde fiction, and the new Chinese cinema. Durham, NC: Duke University Press.

Correct: Zhang, X. (1997). Chinese modernism in the era of reforms: Cultural fever, Avant-Garde fiction, and the new Chinese cinema. Durham, NC: Duke University Press. 